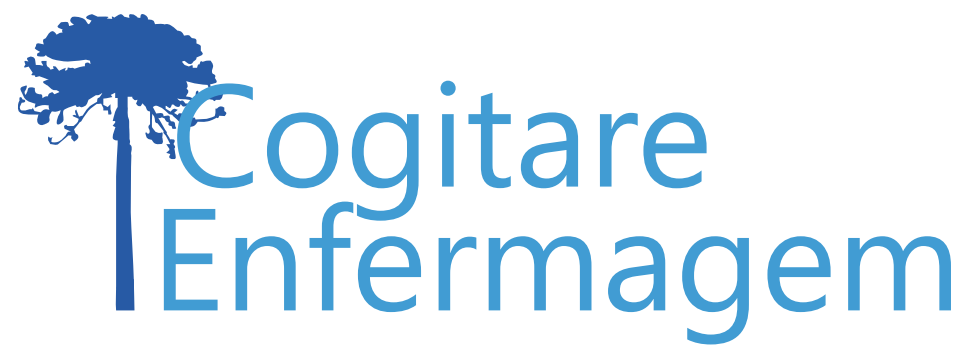

\title{
MOTIVAÇÃO DE ALUNOS DA ÁREA DA SAÚDE EM DISCIPLINAS TOTALMENTE A DISTÂNCIA: INFLUÊNCIA SOCIOECONÔMICA*
}

Fernanda Regina Antunes ${ }^{1}$, Francine da Costa Alves², Alfredo Almeida Pina-Oliveira3, Maíra Rosa Apostolico 4 , Ana Claudia Puggina ${ }^{5}$

\section{RESUMO}

Objetivo: avaliar se as características socioeconômicas de alunos da saúde interferem na motivação no uso das Tecnologias Digitais da Informação e Comunicação.

Método: estudo analítico realizado em 2015 com 713 alunos de graduação da área de saúde. Foi aplicada a Escala de Avaliação de Fatores de Motivação com Relação à Integração das Tecnologias de Informação e Comunicação ao Ensino em uma instituição de Ensino da Região metropolitana de São Paulo.

Resultados: houve significância para o fator Desmotivação entre estudantes com companheiro estável. Menor renda familiar interferiu positivamente nos fatores Controle Externo e Controle Interno. Os semestres iniciais dos cursos implicaram em maiores médias no controle externo, controle interno, controle por identificação e na motivação intrínseca.

Conclusão: o conhecimento da relação entre as características socioeconômicas e os fatores de motivação de estudantes em disciplinas totalmente a distância contribui para o planejamento de abordagens personalizadas e contextualizadas no ensino superior.

DESCRITORES: Educaçãoa Distância; Educação Superior; Tecnologia da Informação; Comunicação; Motivação.

\footnotetext{
*Artigo extraído da dissertação de mestrado "Motivação no uso das tecnologias da informação e comunicação no ensino a distância de alunos da área da saúde". Universidade Guarulhos, 2018.
}

COMO REFERENCIAR ESTE ARTIGO: Antunes FR, Alves F da C, Pina-Oliveira AA, Apostolico MR, Puggina AC. Motivação de alunos da área da saúde em disciplinas totalmente a distância: influência socioeconômica. Cogitare enferm. [Internet]. 2019 [acesso em "colocar data de acesso, dia, mês abreviado e ano"]; 24. Disponível em: http://dx.doi.org/10.5380/ce.v24i0.60243.

Este obra está licenciado com uma Licença Creative Commons Atribuição 4.0 Internacional.

${ }^{1}$ Enfermeira. Mestre em Ciências. Universidade Universus Veritas. Guarulhos, SP, Brasil. 0

${ }^{2}$ Enfermeira. Mestre em Ciências Universidade Universus Veritas. Guarulhos, SP, Brasil.

${ }^{3}$ Enfermeiro. Doutor em Ciências. Docente de Enfermagem da Universidade Universus Veritas. Guarulhos, SP, Brasil. $P$

${ }^{4}$ Enfermeira. Doutora em Ciências. Docente de Enfermagem da Universidade Universus Veritas. Guarulhos, SP, Brasil. ()

${ }^{5}$ Enfermeira. Doutora em Ciências. Docente da Faculdade de Medicina de Jundiaí. Jundiaí, SP, Brasil. (P) 


\title{
MOTIVATION OF HEALTHY AREA STUDENTS IN DISCIPLINES THAT ARE 100\% DISTANCE EDUCATION: SOCIOECONOMIC INFLUENCE
}

\begin{abstract}
Objective: to evaluate whether the socioeconomic characteristics of health area students affect motivation in the use of Digital Information and Communication Technologies.

Method: an analytical study was carried out in 2015 with 713 undergraduate students of the health area. The Scale of Evaluation of Motivation Factors with regard to the Integration of Information and Communication Technologies into Teaching was applied in a teaching institution of the metropolitan region of São Paulo.

Results: the Demotivation factor was significant among students with stable partners. Lower family income positively affected the External Control and Internal Control factors. The initial semesters of the courses presented higher means in external control, internal control, control by identification and intrinsic motivation.

Conclusion: the knowledge of the relationship between the socioeconomic characteristics and the motivation factors of students in distance education disciplines contributes to the planning of personalized and contextualized approaches in higher education.
\end{abstract}

DESCRIPTORS: Distance Education; Higher education; Information Technology; Communication; Motivation.

\section{MOTIVACIÓN DE ALUMNOS DEL ÁREA DE SALUD EN ASIGNATURAS ENTERAMENTE A DISTANCIA: INFLUENCIA SOCIOECONÓMICA}

\section{RESUMEN:}

Objetivo: evaluar cuánto las características socioeconómicas de alumnos del área de la salud influyen en la motivación en el uso de las Tecnologías Digitales de la Información y Comunicación.

Método: estudio analítico que se realizó en 2015 con 713 alumnos de enseñanza superior en área de salud. Se utilizó la Escala de Evaluación de Factores de Motivación con Relación a la Integración de las Tecnologías de Información y Comunicación a la Enseñanza en una institución de Enseñanza de la Región metropolitana de São Paulo.

Resultados: hubo significancia para el factor Desmotivación entre estudiantes con pareja estable. Menor renta familiar influyó positivamente en los factores Control Externo y Control Interno. Los semestres iniciales de los cursos presentaron mayores promedios en el control externo, control interno, control por identificación y en la motivación intrínseca.

Conclusión: el conocimiento acerca de las características socioeconómicas y los factores de motivación de estudiantes en asignaturas enteramente a distancia contribuye para el planeamiento de abordajes personalizados y contextualizadas en la enseñanza superior.

DESCRIPTORES: Educación a Distancia; Enseñanza Superior; Tecnología de la Información; Comunicación; Motivación. 
Educação a Distância ( $\mathrm{EaD})$ pode ser definida como processo de ensino-aprendizagem mediado por ferramentas digitais, em que professores e alunos estão separados espacial e/ou temporalmente, mas podem estar conectados, interligados por tecnologias, em especial as telemáticas, como a internet ${ }^{(1-2)}$.

As Tecnologias Digitais da Informação e Comunicação (TDIC) contribuem com a EaD e permitem a transmissão, disseminação, transformação, armazenamento, comunicação e criação de conteúdos que podem ou não estar ligados a uma metodologia de ensino mais dinẩmica, colaborativa e interativa ${ }^{(1)}$.

Nesse sentido, em um mundo em constantes transformações, o papel do docente necessita ser revisitado a fim de produzir práticas educativas presenciais e ou a distância que primem pela mediação pedagógica entre os sujeitos e os objetos de conhecimento na era digital. Trata-se de uma docência em "modo beta"(3), isto é, permanentemente inacabada e com muitas potencialidades e muitos desafios para ser consolidada.

No Brasil, a Lei de Diretrizes e Bases 9.394/96 regulamentou o credenciamento de instituições para oferta de cursos ou programas, na modalidade a distância, para educação básica de jovens e adultos, educação profissional de nível médio e educação superior ${ }^{(4)}$. Ao Ministério da Educação compete o credenciamento institucional, a supervisão, o acompanhamento e a avaliação relacionada com os padrões de qualidade ${ }^{(5)}$.

O Decreto 9.057/2017 representa um novo marco regulatório para a EaD no Brasil e regulamenta a possibilidade de oferta de cursos superiores de graduação e pós-graduação a distância. Contudo, não permite a formação totalmente virtual e as avaliações, estágios, laboratórios ainda permaneceram na modalidade presencial(6-7).

A EaD se tornou frequente pela onipresença das TDIC. Torna-se necessário compreender que o aluno deve ter estrutura física digital mínima, para garantir o acesso em diferentes tempos e espaços presenciais e virtuais ${ }^{(8-9)}$.

A aprendizagem em ambientes virtuais requer do aluno disponibilidade, comprometimento, organização para o estudo, maturidade intelectual e autoconhecimento das próprias necessidades e limites ${ }^{(1,9)}$. Entretanto, a motivação pode variar entre intrínseca, em que a pessoa se sente autodeterminada em realizar uma atividade, ou extrínseca, quando há uma preocupação no cumprimento de uma tarefa por recompensas externas ${ }^{(10)}$.

Na educação, a motivação está associada ao envolvimento dos alunos em desafios, à variedade de estratégias e ao desenvolvimento de tarefas que contribuem positivamente para a aprendizagem ${ }^{(11)}$. Contudo, a motivação no uso das TDIC extrapola a dimensão individual e abarca o contexto socioeconômico, pois a realidade brasileira revela desigualdades sociais que comprometem o acesso a bens e serviços, tais como a educação e os avanços tecnológicos ${ }^{(12)}$.

Com base nesse cenário educacional em constantes transformações, objetivou-se avaliar se as características socioeconômicas de alunos da área da saúde interferem na motivação no uso das TDIC.

\section{MÉTODO}

Estudo analítico e transversal cuja variável dependente é a motivação no uso das TDIC no ensino e as variáveis independentes são as características socioeconômicas de estudantes de uma Instituição de Ensino Superior (IES) privada paulista, de maio de 2015 a setembro de 2015. 
Havia 22 disciplinas totalmente a distância, sendo 19 oferecidas aos cursos de graduação da área da saúde e o ambiente virtual de aprendizagem utilizado era o Modular Object-Oriented Dynamic Learning Environment (Moodle). Os alunos deveriam cumprir de quatro a seis disciplinas desta modalidade de ensino em sua formação.

Essas disciplinas seguiam uma estrutura de oito unidades com duas aulas cada e com conteúdo apenas textual em Portable Document Format (PDF). No final de cada unidade, o aluno respondia um teste com dez questões de múltipla escolha com cinco alternativas. Fórum e atividade contextualizada (elaboração de texto sobre temas específicos) complementavam tais estratégias de ensino.

Foi realizado o cálculo da amostra representativa para a população de cada curso no programa estatístico STATS 2.0, considerando a porcentagem máxima aceitável de erro de $5 \%$, o nível de percentagem estimada de $50 \%$ e o nível de confiança de $95 \%$. Frente às populações de 656 alunos de Enfermagem, 234 de Biomedicina, 361 de Educação Física e 220 de Farmácia, as amostras mínimas representativas obtidas foram respectivamente: $242,145,186$ e 140 alunos.

Os alunos foram recrutados pelo pesquisador no intervalo das aulas e mediante autorização dos professores das disciplinas presenciais. Critérios de inclusão: ter 18 anos ou mais, ter cursado uma disciplina de ensino a distância na IES estudada e estar cursando do $2^{\circ}$ ao $8^{\circ}$ semestre.

Foi utilizada a Escala de Avaliação de Fatores de Motivação com Relação à Integração das Tecnologias de Informação e Comunicação ao Ensino (EMITICE), instrumento psicométrico construído com base na Teoria da Autodeterminação, que objetiva compreender os componentes da motivação intrínseca, motivação extrínseca e desmotivação(10). Dessa forma, a personalidade e a motivação humana concentram-se nas tendências evolutivas, nas necessidades psicológicas inatas, nas condições favoráveis à motivação, no funcionamento social e bem-estar pessoal ${ }^{(13)}$.

Para compreender as dimensões da EMITICE, os autores ${ }^{(13)}$ defendem que a motivação intrínseca se refere ao impulso para fazer algo cujo interesse pela ação é agradável ao indivíduo e está de acordo com seus valores, necessidades e vontades. A desmotivação, por outro lado, se refere à ausência desse impulso. O controle externo está relacionado aos comportamentos regulados pelo interesse em uma recompensa externa; o controle interno se caracteriza pela internalização de uma fonte externa de motivação como forma de satisfazer a necessidade de aceitação ou autoestima. O fator controle por identificação representa as ações tomadas pelo indivíduo quando não existe possibilidade de escolha, dado o contexto em que se insere.

Apesar da EMITICE se referir ao uso geral de TDIC no ambiente universitário, neste estudo os participantes responderam o questionário com enfoque no uso das TDIC das disciplinas on-line oferecidas pela IES.

A escala apresenta 20 afirmativas e foi aplicada, como propõe o estudo de validação da escala original em língua francesa, com os itens randomizados. Os itens da escala são avaliados por uma escala de medida tipo Likert de 7 pontos: (1) Não corresponde absolutamente, (2) Corresponde muito pouco, (3) Corresponde pouco, (4) Corresponde moderadamente, (5) Corresponde bastante, (6) Corresponde fortemente e (7) Corresponde absolutamente ${ }^{(13)}$.

A escala apresenta cinco fatores: Desmotivação (itens 3, 8, 13, 18), Controle Externo $(6,11,16)$, Controle Interno (itens 4, 9, 14, 19), Controle por Identificação (itens 2, 7, 12, 17) e Motivação Intrínseca $(1,5,10,15,20)$. O escore total é obtido pela somatória das respostas e após a recodificação dos itens do fator Desmotivação. O escore total varia de 20 a 140 e quanto maior o escore total, maior a motivação no uso de TDIC na educação a distância(13).

O questionário de caracterização do participante construído contém seis itens sobre 
características socioeconômicas (sexo, idade, estado civil, renda familiar, curso e semestre).

Foi realizada a análise descritiva dos dados por meio de frequências absolutas e relativas, medidas de tendência central (média e mediana) e dispersão (desvio padrão, valores mínimo e máximo). Quanto à análise inferencial, foi avaliada a normalidade do escore total EMITICE e dos fatores pelo teste de Komolgorov-Smirnov; como estes não apresentaram distribuição normal, foram aplicados testes não paramétricos. Na comparação dos escores aplicou-se o teste de Mann-Whitney e, na comparação com variáveis com três grupos ou mais, utilizou-se o teste de Kruskal-Wallis. Neste último caso, quando a diferença significativa foi observada, aplicou-se o teste post hoc de Dunn.

Na comparação entre variáveis quantitativas foi utilizado o teste de correlação de Spearman $(r)$. Os valores de referência para a magnitude foram: $r=0,10$ até 0,39, fraco; $r=0,40$ até 0,69 , moderado; $r=0,70$ até 1 , forte ${ }^{(14)}$.

Assumiu-se um nível descritivo de $5 \%(p<0,05)$ para significância. Os dados foram


versão 22.0 para Windows ${ }^{\circledR}$ e Graph Pad.

Destaca-se neste estudo que algumas variáveis sofreram o processo de imputação de dados pela moda ${ }^{(15)}$ e que não houve diferença na distribuição das medidas de tendência central e dispersão das variáveis, pois as perdas oscilaram entre 0,1\% e 1,8\%.

O presente estudo foi aprovado pelo Comitê de Ética em Pesquisa da Universidade Guarulhos sob número de parecer 512.813.

\section{RESULTADOS}

Participaram do estudo 713 alunos com média de idade de 26,6 anos $( \pm 7,1), 64,6 \%$ do sexo feminino, $70 \%$ solteiras e com renda familiar média de 3,9 salários mínimos (Tabela 1).

Tabela 1 - Número e percentual de alunos, segundo características socioeconômicas e acadêmicas $(n=713)$. Guarulhos, SP, Brasil, 2016

\begin{tabular}{lcclcc} 
Variável e Categorias & $\mathbf{n}$ & $\%$ & Variável e Categorias & $\mathbf{n}$ & $\%$ \\
\hline Sexo* & \multicolumn{7}{c}{ Semestre* } \\
\hline Feminino & 461 & 64,6 & $2^{\circ}$ & 98 & 13,7 \\
\hline Masculino & 252 & 35,4 & $3^{\circ}$ & 155 & 21,7 \\
\hline Estado civil & & & $4^{\circ}$ & 145 & 20,3 \\
\hline Solteiro & 499 & 70 & $5^{\circ}$ & 121 & 17 \\
\hline Casado & 156 & 21,9 & $6^{\circ}$ & 54 & 7,6 \\
\hline Convivente ou união estável & 24 & 3,4 & $7^{\circ}$ & 100 & 14 \\
\hline Separado & 7 & 1 & $8^{\circ}$ & 40 & 5,6 \\
\hline Divorciado & 26 & 3,6 & Curso & 145 & 20,3 \\
\hline Viúvo & 1 & 0,1 & Biomedicina & 182 & 25,5 \\
\hline & & & Educação física & 246 & 34,5 \\
\cline { 3 - 7 } & & & Enfermagem & 140 & 19,6 \\
\cline { 3 - 6 } & 713 & 100 & Total & 713 & 100
\end{tabular}

Nota:* imputação 0,4\% da variável; ** imputação 0,1\% da variável 
Considerando os valores das médias de tendência central e de dispersão para cada item que compõe o escore EMITICE, os valores medianos mais elevados foram para os quatro itens que abarcam o fator Desmotivação, mostrando que os alunos têm impressão de perder tempo realizando a disciplina on-line, não compreendem a relevância de aprender com as tecnologias, do porquê das solicitações de TDIC nos trabalhos acadêmicos e da utilização das TDIC nas aulas. Os itens com menores médias indicam que os alunos utilizam as TDIC mais por obrigação do que por prazer (Tabela 2).

Tabela 2 - Análise descritiva dos itens do instrumento EMITICE (n=713). Guarulhos, SP, Brasil, 2016

Item Variáveis

3 Tenho a impressão de perder meu tempo utilizando as TIC.*

8 Eu não compreendo a relevância de aprender com as tecnologias. §§

18 Eu não sei por que eu utilizo as TIC nas minhas aulas na universidade. **

13 Eu não vejo porquê somos solicitados a utilizar as TIC nos trabalhos. ***

2 Porque, a meu ver, o conhecimento das TIC ajudará a me preparar melhor para a minha futura profissão.§§

12 Porque isso vai me ajudar a estar mais bem preparado(a) e instrumentalizado(a) para a carreira que escolhi.**

17 Porque eu acredito que um melhor domínio das TIC vai aumentar minha competência profissional.

\begin{tabular}{|c|c|c|c|}
\hline 19 & Porque, na nossa época, devemos utilizar as TIC na educação. & 4 & 1,7 \\
\hline 11 & $\begin{array}{l}\text { Porque é um diferencial para obter um trabalho estável ao final dos meus } \\
\text { estudos. ¥¥ }\end{array}$ & 3,9 & 1,7 \\
\hline 20 & Porque aprender com a ajuda das TIC é interessante. & 3,9 & 1,7 \\
\hline 7 & 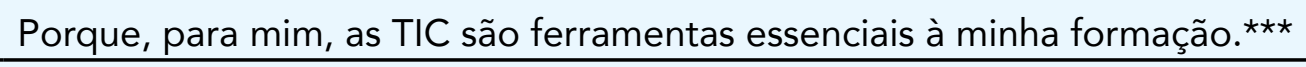 & 3,8 & 1,7 \\
\hline 9 & 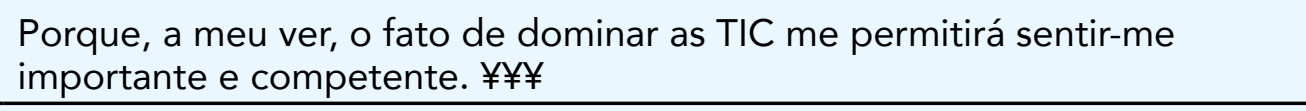 & 3,7 & 1,6 \\
\hline 16 & Porque isso tornará a minha atividade profissional mais interessante.§ & 3,7 & 1,6 \\
\hline 4 & Para provar a mim mesmo(a) que sou capaz de aprender com as TIC. ${ }^{\star \star \star \star}$ & 3,6 & 1,6 \\
\hline 10 & Porque aprender com as TIC é estimulante. $¥$ & 3,6 & 1,7 \\
\hline 14 & $\begin{array}{l}\text { Para provar a mim mesmo(a) que sou uma pessoa inteligente, capaz de } \\
\text { aprender por meio das TIC. } \S \S \S\end{array}$ & 3,6 & 1,6 \\
\hline 15 & Pelo prazer de realizar trabalhos ou projetos com a ajuda das TIC.** & 3,6 & 1,6 \\
\hline 5 & Porque eu gosto muito de utilizar as TIC. $\S \S \S$ & 3,5 & 1,7 \\
\hline 6 & $\begin{array}{l}\text { Porque não existem outras formas de se sair bem em certos cursos na } \\
\text { Universidade. } ¥\end{array}$ & 3,4 & 1,7 \\
\hline 1 & Porque tenho prazer em fazê-lo.* & 3,2 & 1,6 \\
\hline
\end{tabular}

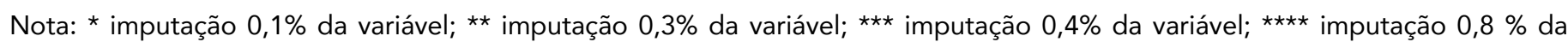
variável; ¥ imputação $1,0 \%$ da variável; ¥¥ imputação 1,1\% da variável; ¥¥¥imputação 1,3\% da variável; § imputação 1,4\% da variável; §§ imputação 1,7\% da variável; §§§ imputação 1,8\% da variável; O termo Tecnologia da Informação e da Comunicação (TIC) foi proposto pelo autor do instrumento, mas refere-se diretamente às TDIC 
O escore total médio da EMITICE na amostra foi de $78,5( \pm 20,4)$, abaixo do ponto médio do instrumento (80) e que corresponde à motivação de baixa a moderada. Realizada a normalização a 100 para possibilitar a comparação entre os fatores, foi possível identificar que o fator Desmotivação obteve o maior escore. Fica observada a baixa Motivação Intrínseca comparada com os outros fatores (Tabela 3).

Tabela 3 - Análise descritiva dos fatores e escore total do instrumento EMITICE ( $n=713)$. Guarulhos, SP, Brasil, 2016

\begin{tabular}{lccccccc} 
Variáveis & $\begin{array}{c}\mathbf{N}^{\circ} \text { de } \\
\text { itens }\end{array}$ & Média & $\begin{array}{c}\text { Normalização } \\
\text { a 100 }\end{array}$ & DP & Mediana & Mínimo & Máximo \\
\hline Escore total & 20 & 78,5 & 56,1 & 20,4 & 80 & 22 & 140 \\
\hline Fatores & & & & & & & \\
\hline Desmotivação & 4 & 18,7 & 66,8 & 5,4 & 19 & 4 & 28 \\
\hline Controle externo & 3 & 11,1 & 52,9 & 4,1 & 11 & 3 & 21 \\
\hline Controle interno & 4 & 15 & 53,6 & 5,3 & 16 & 4 & 28 \\
\hline Controle por identificação & 4 & 15,7 & 56,1 & 5,8 & 16 & 4 & 28 \\
\hline Motivação intrínseca & 5 & 17,8 & 50,9 & 6,7 & 18 & 5 & 35
\end{tabular}

A variável idade do aluno não apresentou correlação significativa com os escores dos fatores Desmotivação $(r=0,02 ; p=0,55)$, Controle Externo $(r=-0,00 ; p=0,96)$, Controle Interno $(r=-0,03 ; p=0,44)$, Controle por Identificação $(r=-0,05 ; p=0,17)$ e Motivação Intrínseca $(r=-0,01 ; p=0,76)$.

Houve diferença significativa entre as variáveis estado civil e curso com o fator Desmotivação. Para o estado civil, verificou-se média superior para desmotivação quando há um companheiro estável. Quanto ao curso, observa-se desmotivação superior no curso de Farmácia em relação ao curso de Biomedicina (Tabela 4).

Tabela 4 - Comparação significativa das variáveis socioeconômicas segundo os escores dos fatores do instrumento EMITICE ( $n=713)$. Guarulhos, SP, Brasil, 2016 (continua)

\begin{tabular}{lccccccc} 
Variáveis & $\mathbf{n}$ & Média & DP & Mediana & Mínimo & Máximo & p-valor \\
\hline Estado civil* & & & & & & & \\
\hline Sem companheiro & 533 & 18,6 & 5,4 & 19 & 4 & 28 & 0,03 \\
\hline Com companheiro & 180 & 19,7 & 5,2 & 20 & 4 & 28 & \\
\hline Curso & & & & & & & \\
\hline Biomedicina & 145 & 17,9 & 5,3 & 18 & 4 & 28 & 0,03 \\
\hline Educação Física & 182 & 18,7 & 5,2 & 19 & 4 & 28 & \\
\hline Enfermagem & 246 & 19 & 5,7 & 19 & 4 & 28 & \\
\hline Farmácia & 140 & 19,8 & 5 & 19,5 & 4 & 28 & \\
\hline
\end{tabular}


Controle Externo

Renda Familiar

\begin{tabular}{lccccccc}
\hline 1 a 3 salários mínimos & 372 & 11,4 & 4,3 & 12 & 3 & 21 & 0,04 \\
\hline 4 a 6 salários mínimos & 257 & 10,7 & 3,8 & 11 & 3 & 21 & \\
\hline 7 ou mais salários mínimos & 84 & 10,5 & 4,1 & 11 & 3 & 21 & \\
\hline Semestre* $^{\circ}$ & & & & & & & \\
\hline $2^{\circ}$ ao $4^{\circ}$ & 398 & 11,4 & 4,1 & 12 & 3 & 21 & 0,02 \\
\hline $5^{\circ}$ ao $6^{\circ}$ & 315 & 10,7 & 4,1 & 11 & 3 & 21 & \\
\hline
\end{tabular}

Controle Interno

Renda Familiar

\begin{tabular}{lccccccc}
\hline 1 a 3 salários mínimos & 372 & 15,4 & 5,6 & 16 & 4 & 28 & 0,02 \\
\hline 4 a 6 salários mínimos & 257 & 14,6 & 4,7 & 15 & 4 & 28 & \\
\hline 7 ou mais salários mínimos & 84 & 14 & 6 & 15 & 4 & 28 & \\
\hline
\end{tabular}

Semestre*

\begin{tabular}{cccccccc}
\hline $2^{\circ}$ ao $4^{\circ}$ & 398 & 15,3 & 5,4 & 16 & 4 & 28 & 0,04 \\
\hline $5^{\circ}$ ao $6^{\circ}$ & 315 & 14,5 & 5,3 & 15 & 4 & 28 & \\
\hline
\end{tabular}

Controle por Identificação

Semestre*

\begin{tabular}{llllllll}
\hline $2^{\circ}$ ao $4^{\circ}$ & 398 & 16,2 & 5,8 & 16 & 4 & 28 & 0,01 \\
\hline $5^{\circ}$ ao $6^{\circ}$ & 315 & 15,1 & 5,7 & 15 & 4 & 28 \\
\hline \multicolumn{8}{c}{ Motivação Intrínseca } \\
\hline
\end{tabular}

Semestre*

\begin{tabular}{llllllll}
\hline $2^{\circ}$ ao $4^{\circ}$ & 398 & 18,3 & 6,6 & 19 & 5 & 35 & 0,02 \\
\hline $5^{\circ}$ ao $6^{\circ}$ & 315 & 17,2 & 6,7 & 17 & 5 & 35 &
\end{tabular}

Nota: Teste Kruskal-Wallis / *Teste Mann Whitney

Nos fatores Controle Externo e Controle Interno houve diferença significativa com a variável renda familiar. Esses dados mostram que alunos com renda familiar entre 1 e 3 salários mínimos apresentaram maiores médias tanto no controle externo quanto no interno (Tabela 4).

A variável semestre apresentou diferença significativa quando comparada com os fatores Controle Externo, Controle Interno, Controle por Identificação e Motivação Intrínseca. Os alunos que cursam do $2^{\circ}$ ao $4^{\circ}$ semestre obtiveram escores médios maiores nesses fatores em comparação àqueles do $5^{\circ}$ ao $8^{\circ}$ semestre (Tabela 4).

A Figura 1 destaca a influência positiva da renda no controle externo e interno do indivíduo em relação ao uso das tecnologias digitais, em que os participantes com menor renda (1 a 3 salários mínimos) foram os que mais conseguiram direcionar comportamentos visualizando recompensas externas e satisfação interna via realização das disciplinas que utilizam os recursos digitais como forma de comunicação e aprendizagem. 
A

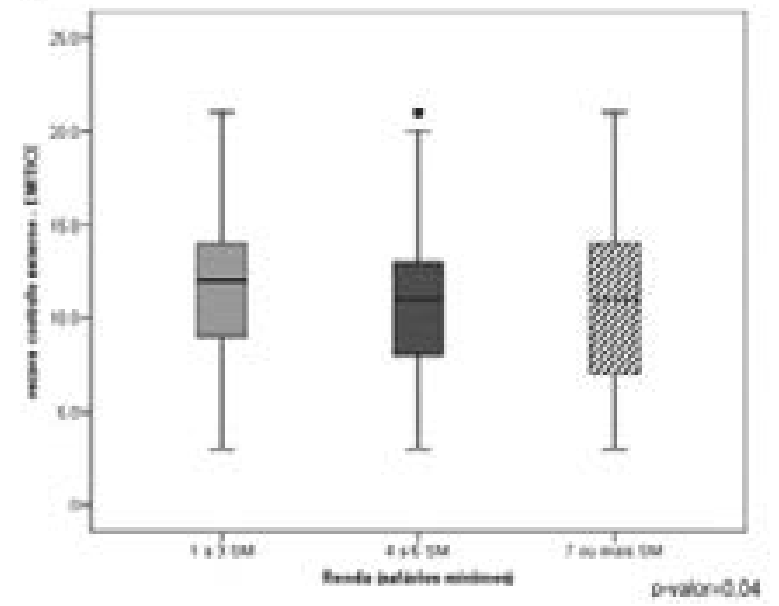

B



Figura 1 - Associações significativas da variável renda em salários mínimos com a EMITICE ( $n=713)$. Guarulhos, SP, Brasil, 2016

Legenda: SM: salários mínimos. p-valor: nível de significância. Resultado da comparação dois a dois pelo teste post hoc de Dunn: A: a diferença foi entre os alunos que recebem entre 1 e 3 SM versus 4 e 6 SM. B: a diferença foi entre alunos que recebem entre 1 e 3 SM versus 7 ou mais SM. A e B: Teste Kruskal-Wallis.

\section{DISCUSSÃO}

Neste estudo, os participantes apresentaram média de idade alta para universitários, indicando investimento tardio na educação superior. De acordo com o Censo da Educação Superior do Ministério da Educação de 2009, a média de idade dos universitários era de 21 anos. Eles geralmente ingressam por meio de vestibular, aos 19 anos, em cursos de bacharelado em instituições particulares e a idade mais frequente de conclusão do curso é de 23 anos $^{(16)}$.

Ao considerar a média de idade encontrada neste estudo, pode-se constatar que a maioria dos participantes integra uma geração jovem caracterizada pela fluência digital, o que justifica essa variável não ter interferido significantemente em nenhum dos fatores da EMITICE.

Outro dado que deve ser destacado é a renda familiar média de 3,9 salários mínimos dos alunos neste estudo, valor que converge com o contexto econômico da região. A IES estudada localiza-se em um município da Região Metropolitana de São Paulo com condições econômicas inferiores, uma vez que a renda domiciliar per capita da cidade de São Paulo correspondia a 1,8 vezes a do município estudado (R\$1.516,21 versus $R \$$ $829,91)$ segundo censo do Instituto Brasileiro de Geografia e Estatística (IBGE)(17).

A renda familiar influencia em determinados padrões de aprendizagem. Estudo realizado no Reino Unido ${ }^{(18)}$ identificou que estudantes com renda familiar elevada foram propensos a exibir um padrão de aprendizagem direcionado ao significado (aprendizagem significativa), enquanto aqueles com baixa renda apresentavam maior probabilidade de exibir um padrão de aprendizagem dirigido pela reprodução (aprendizagem mecânica). Abordagem com significação e reprodução produzem resultados muito diferentes na aprendizagem $^{(19)}$.

Apesar de estudos anteriores apontarem a baixa renda como fator desfavorável ao processo de aprendizagem ${ }^{(17-19)}$, neste estudo os indivíduos inseridos em uma família com menor renda (de 1 a 3 salários mínimos) apresentaram maior controle externo e interno em relação ao uso das TDIC. Esses participantes mostraram mais disposição para 
comportamentos regulados por meios externos e internos para busca de recompensas e melhora da autoestima.

A baixa renda foi uma interferência positiva na motivação no uso das TDIC, pois indivíduos nesta condição socioeconômica tendem a chegar ao ensino superior mais determinados, com mais idade e investem na educação como uma oportunidade de mudar a situação atual de vida. Ainda assim, a desmotivação foi predominante no contexto geral e o fator que obteve a maior média em comparação com os outros.

Os estudantes do $2^{\circ}$ ao $4^{\circ}$ semestre se destacaram quanto à motivação, pois apresentaram maiores médias em relação aos fatores Controle Externo, Controle Interno, Controle por Identificação e Motivação Intrínseca. Esse dado mostra que eles conseguem regular comportamentos por meios externos e internos, agem de maneira efetiva quando não está disponível a escolha, bem como motivam-se gerando um comportamento intencional com base nas próprias necessidades e vontades.

Um estudo quantitativo realizado com estudantes da escola de Educação, Tecnologia e Gestão obteve resultados convergentes em relação ao semestre cursado e motivação no uso das TDIC. Alunos do $2^{\circ}$ ano $\left(3^{\circ}\right.$ e $4^{\circ}$ semestres) atribuíram maior importância ao item estudar individualmente e ao uso dos recursos educativos digitais como enciclopédias online, repositórios científicos e plataformas de e-learning ${ }^{(20)}$.

Neste estudo, há aspectos que podem ter influenciado diretamente a alta desmotivação dos participantes, tais como a estrutura das disciplinas (sempre na mesma forma de apresentação, com pouca inovação e interação) e a estratégia pedagógica (apresentação do conteúdo apenas de forma textual).

O uso de estratégias de ensino criativas e inovadoras possibilita buscas sistematizadas na própria internet e incrementa o interesse dos alunos em cursos completamente on-line ou híbrido. A Aprendizagem Baseada em Problemas ${ }^{(21)}$ enriquecida por TDIC e a utilização de WebQuests ${ }^{22)}$ exemplificam formas de ampliar o aprender a aprender e contemplar níveis mais altos de operações de pensamento para a resolução de problemas durante a graduação em saúde.

A necessidade de uma relação mais direta com o tutor ou docente pode fortalecer a autonomia e a disciplina para realizar os estudos no ambiente virtual, pois a falta de conhecimento para interpretação textual, o acúmulo de tarefas e a perda de prazos pode comprometer o processo de aprendizagem ${ }^{(8)}$.

Como consequência dessas dificuldades em aprender, as disciplinas a distância realizam-se mais por obrigação do que por prazer, convergindo com um dos resultados encontrados no presente estudo. Foi observado pela análise descritiva dos itens da EMITICE que os alunos têm a sensação de perder tempo, não compreensão da relevância de aprender com as tecnologias, do motivo das solicitações de TDIC nos trabalhos acadêmicos e nas aulas.

A relação professor-aluno é um elemento importante no processo de ensinoaprendizagem no espaço da sala de aula, em que o professor deve oferecer oportunidades para que a aula seja de fato um momento de troca, de desenvolvimento de potencialidades, de crescimento intelectual e descoberta de valores que irão contribuir para o seu desenvolvimento pessoal como cidadão e com o futuro profissional(23).

A mediação pedagógica em ambientes virtuais contribui para reafirmar a importância da relação aluno, objeto de conhecimento e professor. Entretanto, o processo de mediar apoiado nas TDIC apresenta certa complexidade, precisa ser aprendido e exige apropriação dessas ferramentas telemáticas pelo professor, de forma a incorporá-los no processo de aprendizagem $^{(24)}$.

As limitações do presente estudo compreendem a não randomização dos participantes, a exclusividade de uma IES avaliada e o tipo de modalidade de ensino 
com foco em conteúdos e perguntas de múltipla escolha como atividades obrigatórias para os alunos. Todavia, a importância deste estudo está em reconhecer as características socioeconômicas dos alunos da IES como elementos que contribuem para o planejamento, a implementação e a avaliação dos cursos e disciplinas EaD.

\section{CONCLUSÃO}

A motivação dos alunos na realização de disciplinas totalmente a distância na IES estudada foi de baixa a moderada. A impressão de perda de tempo, a obrigação por cumprir as tarefas on-line e a falta de compreensão sobre a relevância de aprender e utilizar TDIC nos trabalhos e aulas foram evidenciadas.

A desmotivação foi influenciada pelo estado civil e pelo curso em andamento. A idade não interferiu na motivação dos alunos no uso das TDIC. A renda familiar interferiu positivamente no controle externo e no controle interno dos participantes com menor renda.

O semestre em curso interferiu no controle externo, controle interno, controle por identificação e na motivação intrínseca. Os alunos que estavam cursando do $2^{\circ}$ ao $4^{\circ}$ semestre apresentaram maiores médias em relação aos fatores Controle Externo, Controle Interno, Controle por Identificação e Motivação Intrínseca. Ter companheiro estável e cursar Farmácia se relacionam à desmotivação no uso de TDIC.

\section{REFERÊNCIAS}

1. Moran JM. A educação que desejamos: novos desafios e como chegar lá. 2. ed. Campinas: Papirus; 2007.

2. Moran JM. Ensino e aprendizagem inovadores com tecnologias. Informática na Educação: teoria e prática. [Internet]. 2000 [acesso em 23 nov 2018]; 3(1). Disponível em: https://doi.org/10.22456/19821654.6474.

3. Thadei J. Mediação e educação na atualidade: um diálogo com formadores de professores. In: Moran JM, Bacich L, organizadores. Metodologias ativas para uma educação inovadora: uma abordagem teórico-prática. Porto Alegre: Penso; 2018. p. 91-105.

4. Ministério da Educação (BR). Referenciais de Qualidade para Educação Superior a Distância [Internet]. Brasília. 2007 [acesso em 23 nov 2018]. Disponível em: http://portal.mec.gov.br/seed/arquivos/pdf/ dec 5622.pdf.

5. Ministério da Educação (BR). Decreto n. 5.622, de 19 de dezembro de 2005: regulamenta o Art. 80 da Lei n. 9.394 que estabelece as Diretrizes e Bases da Educação Nacional. Diário Oficial da União [Internet]. 20 dez 2005 [acesso em 23 nov 2018]. Disponível em: http://portal.mec.gov.br/sesu/arquivos/pdf/ portarias/dec5.622.pdf.

6. Ministério da Educação (BR). Decreto n. 9.057, de 25 de maio de 2017: regulamenta o Art. 80 da Lei n. 9.394 que estabelece as Diretrizes e Bases da Educação Nacional e regulamenta a Educação a Distância no país. Diário Oficial da União [Internet]. 26 mai 2017 [acesso em 23 nov 2018]. Disponível em: http:// www.planalto.gov.br/ccivil 03/ Ato2015-2018/2017/Decreto/D9057.htm.

7. Associação Brasileira de Educação a Distância [Internet]. São Paulo: Associação Brasileira de Educação a Distância.. Portaria regulamenta Novo Marco Regulatório da Educação a Distância Brasileira; [15 telas]. São Paulo. 2017 [acesso em 23 nov 2018]. Disponível em: http://www.abed.org.br/arquivos/Artigo Portaria Regulamenta Novo Marco Regulatorio EAD SANTOS JR.pdf.

8. Capeletti AM. Ensino a distância: desafios encontrados por alunos do ensino superior. Rev elet saberes 
da educação. [Internet]. 2014 [acesso em 23 nov 2018]; 5(1). Disponível em: http://docs.uninove.br/arte/ fac/publicacoes pdf/educacao/v5 n1_2014/Aldenice.pdf.

9. Moran JM. Propostas de mudança nos cursos presenciais com a educação "online". Rev ABENO. [Internet]. 2005 [acesso em 12 mar 2019];5(1). Disponível em: http://abeno.org.br/ckfinder/userfiles/files/ revista-abeno-2005-1.pdf.

10. Leal EA, Miranda GJ, Carmo CRS. Teoria da autodeterminação: uma análise da motivação dos estudantes do curso de ciências contábeis. Rev. contab. Finanç. [Internet]. 2013 [acesso em 23 nov 2018]; 24(62). Disponível em: http://dx.doi.org/10.1590/S1519-70772013000200007.

11. Guimarães SER, Boruchovitch E. O estilo motivacional do professor e a motivação intrínseca dos estudantes: uma perspectiva da Teoria da autodeterminação. Psicol. Reflex. Crit. [Internet]. 2004 [acesso em 23 nov 2018]; 17(2). Disponível em: http://dx.doi.org/10.1590/S0102-79722004000200002.

12. Barros RP de, Henriques R, Mendonça R. Desigualdade e pobreza no Brasil: retrato de uma estabilidade inaceitável. Rev. bras. Ci. Soc. [Internet]. 2000 [acesso em 23 nov 2018]; 15(42). Disponível em: http://dx.doi.org/10.1590/S0102-69092000000100009.

13. Fiuza PJ, Sarriera JC, Bedin LM. Educação a distância: tradução, adaptação e validação da escala de motivação EMITICE. Psicol. Esc. Educ. [Internet]. 2013 [acesso em 23 nov 2018]; 17(1). Disponível em: http://dx.doi.org/10.1590/S1413-85572013000100005.

14. Dancey CP, Reidy J. Estatística sem matemática para psicologia: usando SPSS para Windows. Porto Alegre: Artmed; 2006.

15. Farhangfar A. Kurgan L, Pedrycz W. Experimental analysis of methods for imputation of missing values in databases. In: Intelligent Computing: Theory and Applications II. Orlando: The International Society for Optical Engineering; 2004. Disponível em: https://doi.org/10.1117/12.542509.

16. Ministério da Educação (BR). Censo da Educação Superior: principais resultados. [Internet] Brasília: Ministério da Educação: 2016 [acesso em 23 nov 2018]. Disponível em: http://download.inep.gov.br/ educacao superior/censo superior/documentos/2016/censo superior tabelas.pdf.

17. Instituto Brasileiro de Geografia e Estatística (IBGE). Renda domiciliar per capita 2016. [Internet]. Brasília: IBGE; 2016 [acesso em 23 nov 2018]. Disponível em: ftp://ftp.ibge.gov.br/Trabalho e Rendimento/Pesquisa Nacional por Amostra de Domicilios continua/Renda domiciliar per capita/ Renda domiciliar per capita 2016.pdf.

18. Richardson JT. Conceptions of learning and approaches to studying among White and ethnic minority students in distance education. Br J Educ Psychol. [Internet]. 2010 [acesso em 23 nov 2018]; 80(4). Disponível em: https://doi.org/10.1348/000709910X489283.

19. Pontes Neto JAS. Teoria da aprendizagem significativa de David Ausubel: perguntas e respostas. Série-Estudos Periódico do Mestrado em Educação da UCDB. [Internet]. 2006 [acesso em 23 nov 2018]; (21). Disponível: http://www.serie-estudos.ucdb.br/index.php/serie-estudos/article/view/296.

20. Morais NS, Batista J, Ramos F. Impactos associados ao uso de tecnologias da comunicação em contextos de aprendizagem: a percepção e a influência do género nos estudantes do ensino superior português. Indagatio Didactica. [Internet]. 2014 [acesso em 23 nov 2018]; 6(1). Disponível em: http:// revistas.ua.pt/index.php/ID/article/view/2687.

21. Marin JSM, Lima EFG, Paviotti AB, Matsuyama DT, Silva LKD da, Gonzalez C et al. Aspectos das fortalezas e fragilidades das metodologias ativas de aprendizagem. Rev. bras. educ. med. [Internet]. 2010 [acesso em 23 nov 2018]; 34(1). Disponível em: http://dx.doi.org/10.1590/S0100-55022010000100003.

22. Sanford J, Jacobs M, Townsend-Rocchiccioli J. Using the WebQuest to engage learners in the online classroom. Nurse Educ. [Internet]. 2007 [acesso em 23 nov 2018]; 32(5). Disponível em: https://www. nursingcenter.com/pdfjournal?AID=740055\&an=00006223-200709000-00005\&Journal ID=54026\&Issue $\underline{I D}=740040$. 
23. Silva OG da, Navarro EC. A relação professor-aluno no processo ensino aprendizagem. Interdisciplinar. Rev Elet Interdisciplinar. [Internet]. 2012 [acesso em 12 mar 2019]; 2(8). Disponível em: http://cac-php.unioeste.br/programa/pibid/docs/leituras/A\%20rela\%C3\%A7\%C3\%A30\%20professoraluno\%20no\%20processo\%20ensino-aprendizagem.pdf.

24. Peixoto J, Carvalho RMA de. Mediação pedagógica midiatizada pelas tecnologias? Rev Teoria e Prática da Educação. [Internet]. 2011 [acesso em 23 nov 2018]; 14(1). Disponível em: http://eduem.uem. br/ojs/index.php/TeorPratEduc/article/view/15671/8499.

Recebido: 29/06/2018

Finalizado: 23/04/2019

\section{Autor Correspondente:}

Alfredo Almeida Pina-Oliveira

Universidade Universus Veritas

Pç. Tereza Cristina, 229 - 07023-070 - Guarulhos, SP, Brasil

E-mail: alfredo.almeida@prof.ung.br

Contribuição dos autores:

Contribuições substanciais para a concepção ou desenho do estudo; ou a aquisição, análise ou interpretação de dados do estudo - FRA, FCA, AAPO, MRA, ACP

Aprovação da versão final do estudo a ser publicado - AAPO, MRA, ACP 